\title{
Correlation of Serum Nitric Oxide and Urine Malondialdehyde Levels in Non-Hemodialysis Chronic Kidney Disease Patients
}

\author{
Dinda Dwi Purwati ${ }^{1}$, Arifa Mustika ${ }^{2}$, Lukman Hakim${ }^{3}$, Mochammad Thaha ${ }^{4}$ \\ ${ }^{1}$ Medical Program, Faculty of Medicine, Universitas Airlangga, Surabaya, Indonesia \\ ${ }^{2}$ Department of Anatomy, Histology, and Pharmacology, Faculty of Medicine, Universitas Airlangga, Surabaya, Indonesia \\ ${ }^{3}$ Department of Urology, Faculty of Medicine, Universitas Airlangga, Surabaya, Indonesia \\ ${ }^{4}$ Department of Internal Medicine, Faculty of Medicine, Universitas Airlangga, Surabaya, Indonesia
}

Background: In 2017, about 1.2 million people died because of Chronic Kidney Disease (CKD). Patients with CKD are known to have increased levels of oxidative stress which leads to decrease in NO production. NO is a highly reactive signaling molecule and a major determinant of vascular homeostasis. Thus, the decreased NO can be a risk factor for the development of atherosclerosis and increased cardiovascular risk. Meanwhile, Malondialdehyde (MDA) is known as excellent biomarker for oxidative stress. This study aims to determine the correlation of serum total nitric oxide (NO) and urine MDA levels in non-hemodialysis CKD patients.

Materials and Methods: This study was an observational clinical study with a cross sectional design. Fourty-nine CKD subjects were selected by consecutive sampling. The samples for laboratory tests were collected from urine. MDA concentration was measured using the High-Performance Liquid Chromatography (HPLC) kit. NO concentration was measured with Griess reaction method and Total Nitric Oxide Parameter kit. The data were analyzed using the Statistic Package for Social Science (SPPS) software version 16.

Results: The data showed significant negative correlations between MDA with NO $(r=-0.294 ; p=0.041)$.

Conclusion: There was a correlation between serum total NO and urine MDA levels in non-hemodialysis CKD patients.

Keywords: chronic kidney disease, malondialdehyde, nitric oxide, non-hemodialysis

\section{Introduction}

Chronic Kidney Disease (CKD) represents most of the global disease load, but in the last 27 years the CKD load has not decreased as other non-communicable diseases. In 2017, the prevalence of CKD was estimated at $9.1 \%$ in the world population and CKD led to 1.2 million deaths. ${ }^{1}$
The incidence of CKD in Indonesia is $0.38 \%$ of the total Indonesian population of $252,124,458$. So, there are 713,783 people who suffer from CKD in Indonesia. ${ }^{2}$

Oxidative stress increases in patients with $\mathrm{CKD}^{3}$ Oxidative stress is caused by an imbalance between oxidizing and the antioxidant defense system. ${ }^{4}$ Redox imbalances have a negative effect on all the elements of the

Date of submission: November 15, 2021

Last Revised: January 20, 2022

Accepted for publication: January 27, 2022

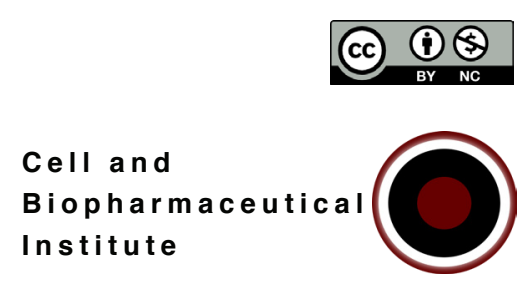

Corresponding Author:

Arifa Mustika

Department of Anatomy, Histology, and Pharmacology

Faculty of Medicine, Universitas Airlangga

Jl. Mayjen Prof. Dr. Moestopo No.47, Surabaya, Indonesia

e-mail: arifa-m@fk.unair.ac.id 
kidney, from the renal circulatory system, the Glomeruli and renal tubules, to interstitial tissues. ${ }^{5}$ It is a risk factor that contributes to the appearance of serious complication of systemic, such as cardiovascular disease, anemia attacked and even mineral disorders. ${ }^{6}$ Level observation Malondialdehyde (MDA) inside the plasma, homogenates of tissues, and also urine has as an excellent technique for predicting oxidative stress levels. ${ }^{7} \mathrm{MDA}$ is claimed to become more mutagenic, then tumorigenic and also more reactive. ${ }^{8}$ The simple and cost-effective process makes MDA routinely used for clinical analysis. ${ }^{9}$ MDA in plasma, serum and urine samples has been used as a biomarker of oxidative stress. ${ }^{10}$ Urine tests are not expensive and most health insurance plans will cover the cost. This test is only a few minutes long. Laboratoriums can provide results for routine testing within one to two days. ${ }^{11}$

There was a study in 50 CKD patients at Jinnah Hospital, Lahore, Pakistan with the results of the study that there was an increase in MDA and a significant decrease in Nitric Oxide (NO) in CKD patients compared to a control sample. Superoxide anion not only activates the monocytes for further issue of inflammatory mediators, but also reacts with $\mathrm{NO}$ to form peroxynitrite $\left(\mathrm{ONOO}^{-}\right)$triggers the peroxidation of lipid and $\mathrm{NO}$ consumption. ${ }^{12} \mathrm{NO}$ is one of the important components of blood vessels, which regulate the main health reporting paths. ${ }^{13}$ In a disease state, NO production is impaired through the production of reactive oxygen and nitric species. ${ }^{14}$

Decreased NO synthesis is known as a sign coming of endothelial dysfunction. In studies with CKD progression, the Endothelial Nitric Oxide Synthase (eNOS) activation pathway was disrupted. Demonstrated by increased phosphorylation of Thr495 eNOS, reduced interaction of eNOS with Hsp90, and eNOS clearance. ${ }^{15}$ Understanding the mechanisms that damage the endothelial function in CKD patients can help design effective strategies to reduce the risk of cardiovascular disease and other complications. ${ }^{16}$

Hemodialysis is a method for removing accumulated toxins in the body and then improving quality of life. ${ }^{17,18} \mathrm{But}$, hemodialysis can also be a factor in increasing oxidative stress and increase the risk of vascular complications. ${ }^{19}$ This is because the low molecular weight antioxidants are filtered out during the method, aggravation of inflammation and Reactive Oxygen Species (ROS) production..$^{20-22}$ Therefore, this study aims to determine the correlation of serum total NO and urine MDA levels in non-hemodialysis chronic kidney disease patients.

\section{Materials and methods}

\section{Study Design and Participants}

This study was an observational clinical study with a cross sectional design. The population of this study were patients who visited Airlangga University Hospital, Surabaya, Indonesia in April-July 2017 with a diagnosis of CKD. Inclusion criteria for this study sample was CKD patients with GFR with minimum stage 1 of KD (less than 60 $\mathrm{mL} / \mathrm{min}$ per $1.73 \mathrm{~m}^{2}$, persisting for 3 months or more). Meanwhile patients receiving $\mathrm{Fe}$ preparations, patients experiencing anemia with hemoglobin levels less than $8 \mathrm{~g} /$ $\mathrm{dL}$, patients experiencing symptoms and signs of infection detected from clinical examination (leukocytes $>11,000 / \mathrm{mcl}$ blood), and patients with CKD who had hemodialysis, were excluded from this study.

Total 49 CKD subjects of both sexes were recruited. All the subjects had agreed and signed the informed consent. All procedures in this experiment had been approved by the Health Research Ethics Committee, Faculty of Medicine, Universitas Airlangga (No.59/EC/KEPK/FKUA/2021).

\section{MDA Measurement}

The concentration of MDA was measured using the HighPerformance Liquid Chromatography (HPLC) kit (Cat No. KC1900, Immunodiagnostic System, East Boldon, UK) consisting of calibrator, control, derivatization solution, reaction solution, and mobile phase in HPLC. The column used is Zorbax Eclipse C18 (Agilent Technologies, Santa Clara, CA, USA) with dimensions of $4.6 \times 150 \mathrm{~mm}, 5 \mu \mathrm{m}$. The HPLC tool used was an Agilent 1260 Binary Pump with a Floresense detector (Agilent Technologies). The HPLC instrument was set to pump the mobile phase at a flow rate of $1 \mathrm{~mL} / \mathrm{min}$ and the column was set at $30^{\circ} \mathrm{C}$. The fluorescent detector was set to excitation wavelength at 515 $\mathrm{nm}$ and emission to $553 \mathrm{~nm}$ with a Photomultiplier (PMT) Gain of 5 times.

The calibrator and controls in the kit were reconstituted by adding $250 \mu \mathrm{L}$ of ultrapure water and then homogenized with a vortex mixer until completely mixed. The calibrators and controls were already in the matrix corresponding to the sample. For the preparation process before entering the HPLC system, the calibrator, control, and urine sample were pipetted $20 \mu \mathrm{L}$ into a test tube, then $1 \mathrm{~mL}$ of derivatization solution was added and homogenized with a vortex mixer for 15 seconds. The mixture was then incubated for 1 hour at $95^{\circ} \mathrm{C}$ until the color changed to reddish. After that, the 
mixture was cooled for 15 minutes at $2-8^{\circ} \mathrm{C}$ and centrifuged at $5000 \mathrm{rpm}$ for 5 minutes.

As much as $500 \mu \mathrm{L}$ of supernatant was added then follow by the addition of $500 \mu \mathrm{L}$ of reagent solution. Homogenized with a vortex mixer until completely mixed, then $20 \mu \mathrm{L}$ of it was injected into the HPLC system. The prepared samples were stable for 4 days at a temperature of $2-8^{\circ} \mathrm{C}$. The concentration of MDA in the sample was obtained quantitatively through a calibration curve consisting of one level with a value of $4.89 \mu \mathrm{mol} / \mathrm{L}$. The detection limit of the method was $0.15 \mu \mathrm{mol} / \mathrm{L}$.

\section{NO Measurement}

The total NO concentration was measured using the nitrite and nitrate measurement approach in the sample using the colorimetric principle with the Griess reaction method. The reagent used was the Total Nitric Oxide Parameter kit (Cat No. KGE001, R\&D systems, Minneapolis, MN, USA). The tool used was Microplate Reader 680 with 96 wellplate format (Biorad, Hercules, CA, USA) and a $10 \mathrm{kDa}$ ultrafilter used was Vivaspin 500 (Sartorius, Göttingen, Germany).

Total of $250 \mu \mathrm{L}$ of serum samples were filtered using a $10 \mathrm{kDa}$ ultrafilter with a centrifugation speed of 14800 RPM for 25 minutes. Then $100 \mu \mathrm{L}$ of the supernatant was diluted 2 times by adding $100 \mu \mathrm{L}$ of the reaction diluent that had previously been diluted 10 times. Calibration standards were prepared by standard reconstitution with a concentration of $2000 \mu \mathrm{mol} / \mathrm{L}$. Then it was diluted 10 times to obtain a standard with a concentration of $200 \mu \mathrm{mol} / \mathrm{L}$ and diluted serially 2 times until the lowest concentration was $3.13 \mu \mathrm{mol} / \mathrm{L}$. Add $50 \mu \mathrm{L}$ of the reaction diluent to each well and add $50 \mu \mathrm{L}$ of the standard and the prepared sample. A total of $25 \mu \mathrm{L}$ of Nicotinamide Adenine Dinucleotide (NADH) was added followed by $25 \mu \mathrm{L}$ of the enzyme nitrate reductase and incubated for 30 minutes at $37^{\circ} \mathrm{C}$. Fifty $\mu \mathrm{L}$ of Griess reagent I was added followed by the addition of 50 $\mu \mathrm{L}$ Griess reagent II, then it was incubated for 10 minutes at room temperature. The absorption was read at a wavelength of $540 \mathrm{~nm}$. The absorption formed would be proportional to the concentration of total NO in the sample obtained by constructing a calibration curve from the standard with a range of 200 to $3.13 \mu \mathrm{mol} / \mathrm{L}$. The detection limit of the method was $0.25 \mu \mathrm{mol} / \mathrm{L}$.

\section{Statistical Analysis}

Data analysis in this study aimed to test the correlation of NO and MDA with a statistical program. The data was analyzed using the Statistic Package for Social Science (SPPS) software version 16 (SPSS Inc., Chicago, IL, USA). Data were analyzed using Spearman's non-parametric correlation test with significance value $p<0.05$.

\section{Results}

\section{Characteristic of Subjects}

In this study, the age of the patients was classified into 2 age groups, namely age $\leq 50$ years and $>50$ years. The results showed that from 49 patients, 5 of them were under 50 years old $(10.2 \%)$ and 44 other patients were over 50 years old (89.8\%). Based on gender, as many as 27 people $(55.1 \%)$ in this study were male and 22 people (44.9\%) were female (Table 1).

\section{Correlation of MDA and NO}

Prior to the analysis, the data for MDA and NO levels were tested for normality to determine the appropriate analytical method. Correlation analysis used was nonparametric Spearman correlation. Based on the calculation of the homogeneity test, a significance value of 0.061 was obtained, which means it was greater than 0.05 . This showed that the variance of the urine MDA variable to Total NO was homogeneous, meant that the distribution of data on the urine MDA variable had the same diversity of values or comes from the same population. With $n=49$, the data showed significant negative correlations between MDA with NO ( $\mathrm{r}=-0.294 ; p=0.041)$ (Figure 1).

\section{Discussion}

The results showed that from 49 patients, 5 of them were under 50 years old $(10.2 \%)$ and 44 other patients were over 50 years old (89.8\%). The stage distribution of CKD prevalence changes significantly, and the prevalence of CKD stages 3 5 increases with age. ${ }^{23}$ Another study found that A person aged $>50$ years old has 3.9 times greater risk of suffering from CKD compared to someone aged 18-50 years old. ${ }^{24}$ Aging can damage the structure and regulatory function of the kidneys. These changes increase the tendency to develop such an Acute Kidney Injury (AKI) and also CKD. ${ }^{25} \mathrm{It}$ is also said that with increasing age, there is a decrease in the size and number of total nephrons, tubulointerstitial changes, thickening of the glomerular basement membrane, and an increase in glomerulosclerosis. ${ }^{26}$ The Indonesian Ministry of Health said that age $>50$ years is included in a high-risk factor for patients with kidney disorders. ${ }^{4}$ 
Table 1. Age and gender distribution of subjects.

\begin{tabular}{|c|c|c|c|}
\hline Age & $\begin{array}{l}\text { Number of } \\
\text { Samples (n) }\end{array}$ & MDA $(\mu \mathrm{mol} / \mathrm{L})$ & $\mathrm{NO}(\mu \mathrm{mol} / \mathrm{L})$ \\
\hline All (Years) & 49 & $5.83 \pm 4.32$ & $67.24 \pm 61.80$ \\
\hline $40-44$ & 1 & 2.9 & 45 \\
\hline $45-49$ & 3 & $5.83 \pm 3.57$ & $52.33 \pm 49.32$ \\
\hline $50-54$ & 7 & $9.87 \pm 7.40$ & $55.29 \pm 13.03$ \\
\hline $55-59$ & 13 & $4.56 \pm 2.30$ & $60.15 \pm 46.89$ \\
\hline $60-64$ & 20 & $5.34 \pm 3.82$ & $74.55 \pm 91.92$ \\
\hline $65-69$ & 5 & $6.02 \pm 3.51$ & $86.60 \pm 66.72$ \\
\hline Male (Years) & 27 & $5.53 \pm 3.79$ & $55.89 \pm 38.60$ \\
\hline $40-44$ & 0 & N.A. & N.A. \\
\hline $45-49$ & 3 & $5.83 \pm 3.57$ & $52.33 \pm 4932$ \\
\hline $50-54$ & 4 & $8.35 \pm 7.34$ & $52.00 \pm 11.40$ \\
\hline $55-59$ & 9 & $4.13 \pm 2.30$ & $63.22 \pm 55.64$ \\
\hline $60-64$ & 7 & $5.00 \pm 2.75$ & $47.00 \pm 19.37$ \\
\hline $65-69$ & 4 & $6.58 \pm 3.80$ & $61.50 \pm 41.67$ \\
\hline Female (Years) & 22 & $6.20 \pm 4.95$ & $81.18 \pm 80.74$ \\
\hline $40-44$ & 1 & 2.9 & 45 \\
\hline $45-49$ & 0 & N.A. & N.A. \\
\hline $50-54$ & 4 & $10.45 \pm 7.55$ & $57.25 \pm 14.12$ \\
\hline $55-59$ & 4 & $5.55 \pm 2.27$ & $53.35 \pm 21.25$ \\
\hline $60-64$ & 13 & $5.53 \pm 4.39$ & $89.38 \pm 98.78$ \\
\hline $65-69$ & 0 & N.A. & N.A. \\
\hline
\end{tabular}

Data are presented as mean values \pm standart deviations when $n>0$, in cases where $n=0$, data are presented as N.A, where N.A.: Not Available.

The results of this study were 27 male (55.1\%), and 22 (44.9\%) females. Male has bad progress to CKD than female because female have a combination of low testosterone and high estrogen plasma levels. sexual hormones have an important role on the development of renal function loss. estrogen has renoprotective effects, reducing albuminuria, attenuating renal lesions, and preventing CKD progression, whereas testosterone stimulates tubular epithelial cell apoptosis, leading to renal damage. ${ }^{2}$ In Indonesia itself the prevalence appeared of CKD which happened to male (4.17\%) was claimed to be higher than female $(3.52 \%) .^{2}$

The results showed that there was a significant (mean) relationship between urine MDA and Total NO. Oxidative stress is said to be involved in various pathological systems in $\mathrm{CKD}$, chronic inflammation triggered by oxidative stress, and chronic degenerative diseases. ${ }^{27}$ Mitochondrial dysfunction and increased mitochondrial ROS are said to be one of the reasons for the increased oxidative stress in CKD. ${ }^{28}$ Mitochondria, Nicotinamide Adenine Dinucleotide
Phosphate (NADPH) oxidase, then Xanthine Oxidase (XO), Myeloperoxidase (MPO), and also eNOS, are stated to become the main sources of ROS formation. ${ }^{29}$

Oxidative stress is characterized by excessive ROS and also Reactive Nitrogen Species (RNS), which are common in kidney disease. ROS is a by-product of aerobic metabolism, including superoxide anion $\left(\mathrm{O}_{2}^{-}\right)$, hydrogen peroxide $\left(\mathrm{H}_{2} \mathrm{O}_{2}\right)$ and hydroxyl radical $\left(\mathrm{OH}^{-}\right)$. superoxide anion $\left(\mathrm{O}_{2}^{-}\right)$can react with $\mathrm{NO}$ to form peroxynitrate $\left(\mathrm{ONOO}^{-}\right),{ }^{30}$ which triggers lipid peroxidation and NO consumption. Due to the process of inactivation from oxygen free radicals and also the conversion of NOS to superoxide generators, oxidative stress leads to a deficiency of NO, which leads to endothelial dysfunction. Decreased NO production leads to decreased endothelium-dependent vasodilation. ${ }^{12}$ Some mechanisms can cause a NO deficiency state. ${ }^{31}$ The NO decrease process is further summarized in Figure 2.

Singlet oxygen is very reactive and attacks lipids or proteins directly to form peroxides. Lipids are the primary 


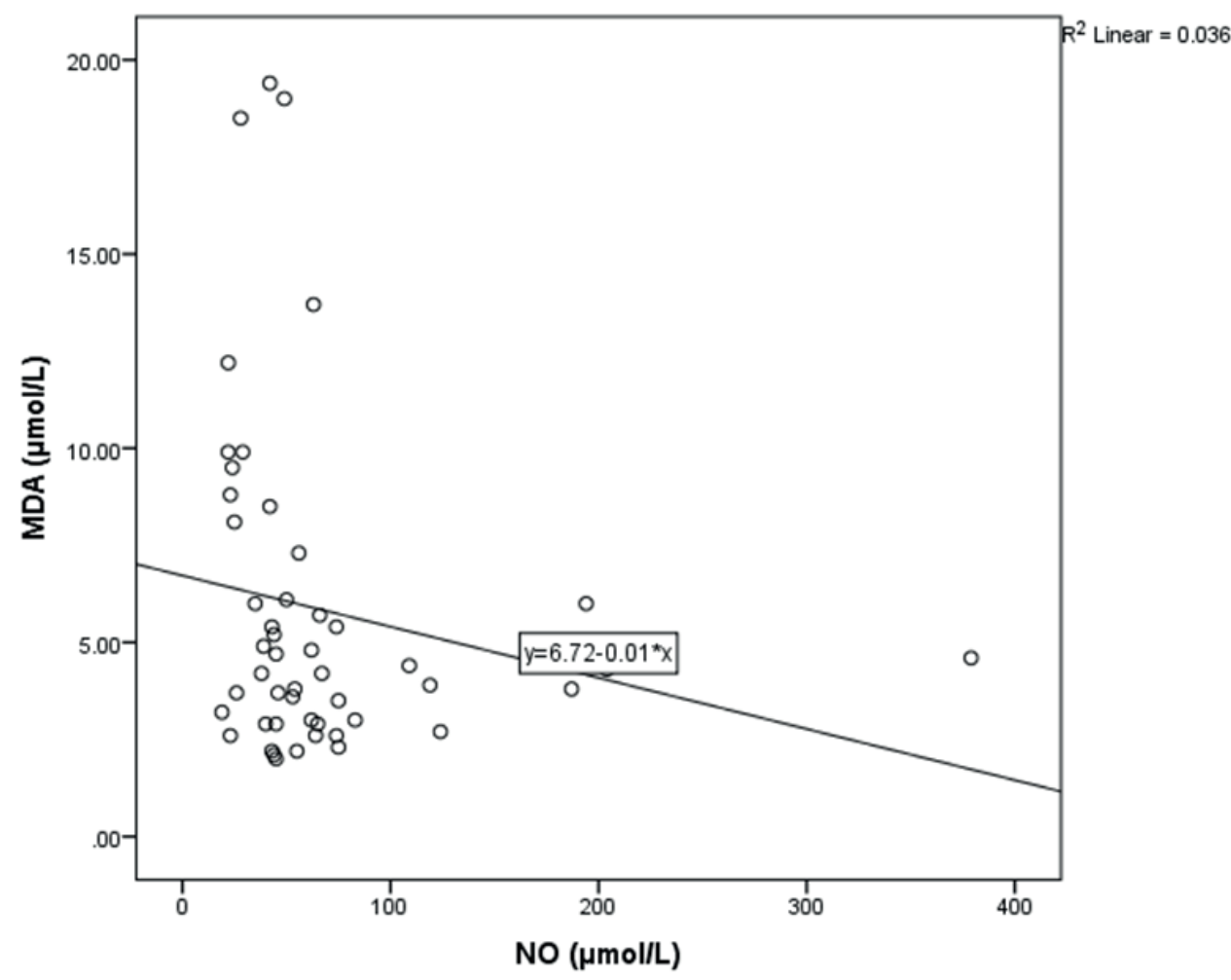

Figure 1. Scatter plot between MDA and NO.

target of membrane oxidation. This is because the methylene bis-allylic carbon present in Polyunsaturated Fatty Acids (PUFAs) is more susceptible to hydrogen abstraction than the allylic carbons of monounsaturated fatty acids. ${ }^{32}$ Lipid peroxidation explained as a process or way that oxidants as like free radicals strike the lipids consisting double bonds of carbon, especially related to PUFA. MDA is known as the most mutagenic product of lipid peroxidation, while 4-Hydroxynonenal (4-HNE) is the most toxic. ${ }^{33}$ There are other ways that can be used to take measurement of oxidative damage, including the modifying proteins and also DNA, however the markers can be created in so many pathways rather than free radicals. In thus, MDA is claimed to become the most outstanding parameter from the oxidative damage into cells and also tissues. ${ }^{34}$ This process is further explained in Figure 3.

This study takes urine samples because urinalysis can be done in a way to take identification about the various

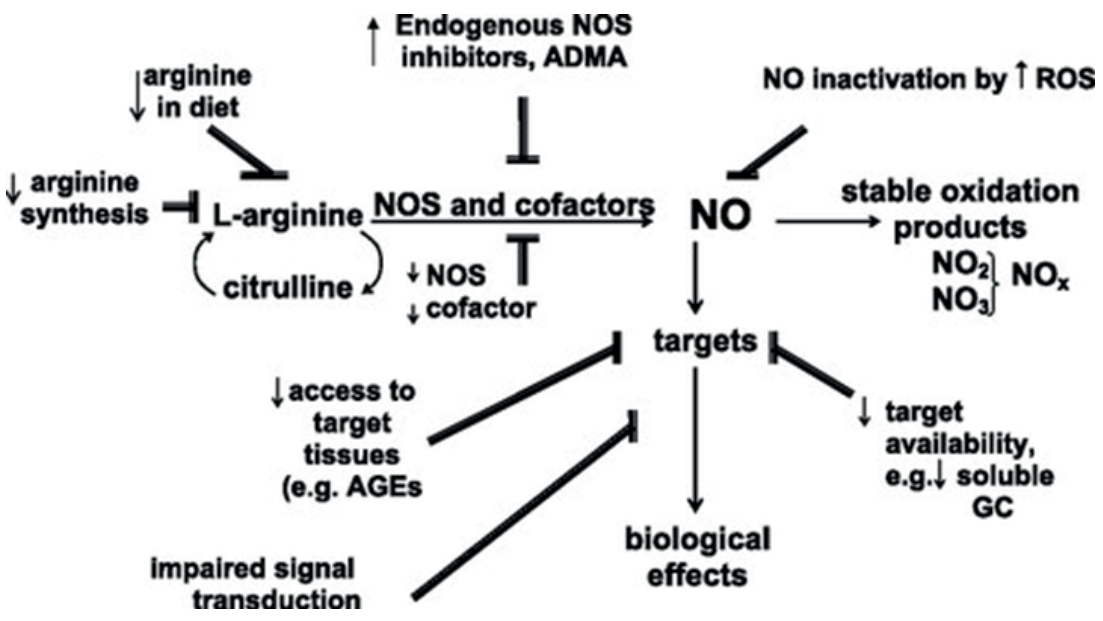

Figure 2. Schematic of mechanisms that can lead to a NO deficiency state. ${ }^{31}$ (Adapted with permission Wolters Kluwer). 


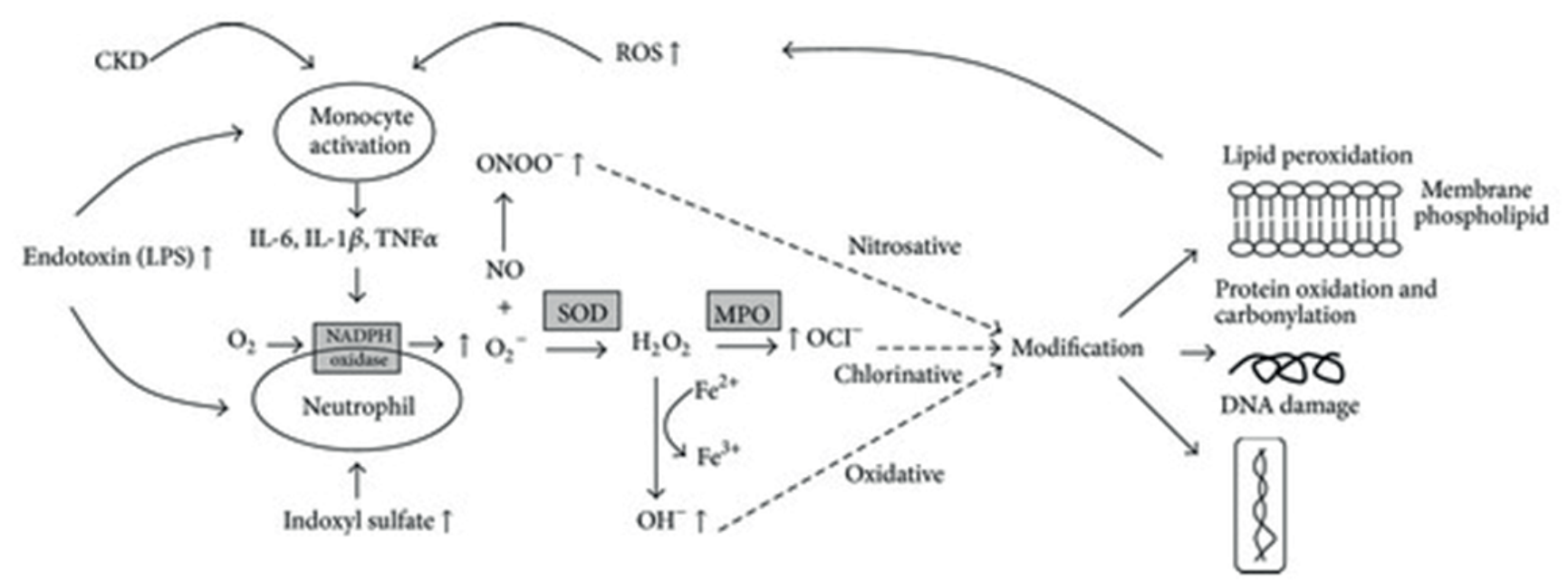

Figure 3. Synthesis of ROS and correlation with NO resulting lipid peroxidation in patients with CKD. ${ }^{35}$ (Adapted with permission from Hindawi).

kidney like CKD. ${ }^{36}$ Taking blood through plasma/serum in CKD patients can cause a significant increase in stress, the risk of infection and vessel injury, has higher organic/ inorganic metals compounds and is said to cause an artificial increase of oxidative stress. Urine is a promising alternative biological fluid for the assessment because it is non-invasive, can be performed without personnel, equipment, or trained personnel, and can be obtained in large quantities multiple times a day.

This study was conducted in patients who have never done hemodialysis because in hemodialysis patients found a statistically significant increase in serum MDA when compared to patients before hemodialysis. Increased oxidative stress status in the hemodialysis patients specifically because of poor dietary intake of the exogenous antioxidants, accumulation the oxidative products, and also loss of antioxidant throughout HD. ${ }^{21}$

\section{Conclusion}

This study showed that there was a correlation between serum total NO and urine MDA levels in non-hemodialysis CKD patients. further studies and explanations are needed to analyze the complications of the disease with an NO decrease and an MDA increasein someone with CKD nonhemodialysis.

\section{Acknowledgements}

This research was under the funding by the rectorate of Universitas Airlangga.

\section{References}

1. Bikbov B, Purcell CA, Levey AS, Smith M, Abdoli A, Abebe M, et al. Global, regional, and national burden of chronic kidney disease, 1990-2017: a systematic analysis for the Global Burden of Disease Study 2017. Lancet. 2020; 395(10225): 709-33.

2. Kementrian Kesehatan RI. Hasil Riset Kesehatan Dasar Kementerian Kesehatan RI 2018. Jakarta: Kementrian Kesehatan RI; 2018.

3. Gyurászová M, Gurecká R, Bábíčková J, Tóthová L. Oxidative Stress in the pathophysiology of kidney disease: implications for noninvasive monitoring and identification of biomarkers. Oxid Med Cell Longev.2020; 2020: 5478708. doi: 10.1155/2020/5478708.

4. Tain YL, Hsu CN. Targeting on asymmetric dimethylarginine-related nitric oxide-reactive oxygen species imbalance to reprogram the development of hypertension. Int J Mol Sci. 2016; 17(12): 2020. doi: 10.3390/ijms17122020.

5. Podkowińska A, Formanowicz D. Chronic kidney disease as oxidative stress-and inflammatory-mediated cardiovascular disease. Antioxidants. 2020; 9(8): 752. doi: 10.3390/antiox9080752.

6. Rapa SF, Di Iorio BR, Campiglia P, Heidland A, Marzocco S. Inflammation and oxidative stress in chronic kidney diseasepotential therapeutic role of minerals, vitamins and plant-derived metabolites. Int J Mol Sci. 2019; 21(1): 263. doi: 10.3390/ ijms21010263.

7. Brombach Zhaw C. Eating practices within a multi-generational approach - A qualitative insight study. Appetite. 2018; 130: 299. doi: 10.15344/2456-8171/2017/122.

8. Annamalay S. Effects of anti-oxidants on oxidative stress: assessing MDA in urine samples. Int J Clin Nutr Diet. 2018; 4(2): 126. doi: 10.15344/2456-8171/2018/126.

9. Ito F, Sono Y, Ito T. Measurement and clinical significance of lipid peroxidation as a biomarker of oxidative stress: Oxidative stress in diabetes, atherosclerosis, and chronic inflammation. Antioxidants. 2019; 8(3): 72. doi: 10.3390/antiox8030072.

10. Farouk A, Hassan MH, Nady MA, Hafez MFA. Role of oxidative stress and outcome of various surgical approaches among patients with bullous lung disease candidate for surgical interference. J Thorac Dis. 2016; 8(10): 2936-41. 
11. National Kidney Foundation. Urinalysis and Kidney Disease: What You Need To Know. New York: National Kidney Foundation; 2014.

12. Rasool M, Ashraf MAB, Malik A, Waquar S, Khan SA, Qazi MH, et al. Comparative study of extrapolative factors linked with oxidative injury and antiinflammatory status in chronic kidney disease patients experiencing cardiovascular distress. PLoS ONE. 2017; 12(2): e0171561. doi: 10.1371/journal.pone.0171561.

13. Ghimire K, Altmann HM, Straub AC, Isenberg JS. Nitric oxide: What's new to NO? Am J Physiol Cell Physiol. 2017; 312(3): C254-62.

14. Cyr AR, Huckaby LV, Shiva SS, Zuckerbraun BS. Nitric oxide and endothelial dysfunction. Crit Care Clin. 2020; 36(2): 307-21.

15. Amador-Martínez I, Pérez-Villalva R, Uribe N, Cortés-González C, Bobadilla NA, Barrera-Chimal J. Reduced endothelial nitric oxide synthase activation contributes to cardiovascular injury during chronic kidney disease progression. Am J Physiol Renal Physiol. 2019; 317(2): F275-85.

16. Martens CR, Kirkman DL, Edwards DG. The vascular endothelium in chronic kidney disease: a novel target for aerobic exercise. Exerc Sport Sci Rev. 2016; 44(1): 12-9.

17. Vadakedath S, Kandi V. Dialysis: a review of the mechanisms underlying complications in the management of chronic renal failure. Cureus. 2017; 9(8): e1603. doi: 10.7759/cureus.1603.

18. Romancito G. Hemodialysis [Internet]. National Institute of Diabetes and Digestive and Kidney Diseases. [updated 2018; cited 2021 Jan 20]. Available from: https://www.niddk.nih.gov/health-information/ kidney-disease/kidney-failure/hemodialysis.

19. Lestaringsih L, Projosudjadi W, Sya'bani M, Hadisaputro S. Correlation between the inflammation factors and intima-media thickness in patients with end-stage renal disease (ESRD) on regular hemodialysis. Mol Cell Biomed Sci. 2019; 3: 48-58.

20. La Russa D, Pellegrino D, Montesanto A, Gigliotti P, Perri A, Russa A La, et al. Oxidative balance and iflammation in hemodialysis patients: biomarkers of cardiovascular risk? Oxid Med Cell Longev. 2019; 2019: 8567275. doi: 10.1155/2019/8567275.

21. Liakopoulos V, Roumeliotis S, Gorny X, Dounousi E, Mertens PR. Oxidative Stress in Hemodialysis Patients: A Review of the Literature. Oxid Med Cell Longev. 2017; 2017: 3081856. doi: $10.1155 / 2017 / 3081856$.

22. Ogunleye A, Akinbodewa AA, Adejumo OA, Oluwafemi TT, Akinfaderin DA. Changes in antioxidant status associated with haemodialysis in chronic kidney disease. Ghana Med J. 2018; 52(1): 29-33.

23. Ji A, Pan C, Wang $\mathrm{H}$, Jin $\mathrm{Z}$, Lee JH, Wu Q, et al. Prevalence and associated risk factors of chronic kidney disease in an elderly population from eastern China. Int J Environ Res Public Health. 2019; 16(22): 4383. doi: 10.3390/ijerph16224383.

24. Ramadhanti R, Helda H. Association of hypertension and chronic kidney disease in population aged $\geq 18$ years old. Mol Cell Biomed Sci. 2021; 5(3): 137-44.

25. Aucella F, Corsonello A, Leosco D, Brunori G, Gesualdo L, Antonelli-Incalzi R. Beyond chronic kidney disease: the diagnosis of renal disease in the elderly as an unmet need. A position paper endorsed by Italian Society of Nephrology (SIN) and Italian Society of Geriatrics and Gerontology (SIGG). J Nephrol. 2019; 32(2): $165-76$.

26. O'Sullivan ED, Hughes J, Ferenbach DA. Renal aging: causes and consequences. J Am Soc Nephrol. 2017; 28(2): 407-20.

27. Daenen K, Andries A, Mekahli D, Van Schepdael A, Jouret F, Bammens B. Oxidative stress in chronic kidney disease. Pediatr Nephrol. 2019; 34(6): 975-91.

28. Galvan DL, Green NH, Danesh FR. The hallmarks of mitochondrial dysfunction in chronic kidney disease. Kidney Int. 2017; 92(5): 1051-7.

29. Di Meo S, Reed TT, Venditti P, Victor VM. Role of ROS and RNS sources in physiological and pathological conditions. Oxid Med Cell Longev. 2016; 2016: 1245049. doi: 10.1155/2016/1245049.

30. Irazabal MV, Torres VE. Reactive oxygen species and redox signaling in chronic kidney disease. Cells. 2020; 9(6): 1342. doi: 10.3390/ cells 9061342.

31. Baylis C. Nitric oxide synthase derangements and hypertension in kidney disease. Curr Opin Nephrol Hypertens. 2012; 21(1): 1-6. doi: 10.1097/MNH.0b013e32834d54ca.

32. Wang TY, Libardo MDJ, Angeles-Boza AM, Pellois JP. Membrane oxidation in cell delivery and cell killing applications. ACS Chem Biol. 2017; 12(5): 1170-82.

33. Ayala A, Muñoz MF, Argüelles S. Lipid peroxidation: production, metabolism, and signaling mechanisms of malondialdehyde and 4-hydroxy-2-nonenal. Oxid Med Cell Longev. 2014; 2014: 360438. doi: $10.1155 / 2014 / 360438$

34. Grotto D, Federal U, Maria DS, Garcia S. Importance of the lipid peroxidation biomarkers and methodological aspects Revisão. Quím Nova. 2009; 32(1): [n.p.]. doi: 10.1590/S010040422009000100032.

35. Sung CC, Hsu YC, Chen CC, Lin YF, Wu CC. Oxidative stress and nucleic acid oxidation in patients with chronic kidney disease. Oxid Med Cell Longev. 2013; 2013: 301982. doi: 10.1155/2013/301982.

36. National Kidney Foundation [Internet]. Tests to Measure Kidney Function, Damage and Detect Abnormalities [cited 2021 Jan 20] Available from: https://www.kidney.org/atoz/content/kidneytests. 